\title{
Landscape genetics of alpine-snowbed plants: comparisons along geographic and snowmelt gradients
}

\author{
AS Hirao and G Kudo \\ Graduate School of Environmental Earth Science, Hokkaido University, Sapporo 060-0810, Japan
}

\begin{abstract}
The genetic structure of three snowbed-herb species (Peucedanum multivittatum, Veronica stelleri, and Gentiana nipponica) was analyzed using allozymes across nine populations arranged as a matrix of three snowmelt gradients $\times$ three geographic locations within $3 \mathrm{~km}$ in the Taisetsu Mountains, northern Japan. Phenologically asynchronous populations are packed within a local area in alpine snowbeds, because flowering season of alpine plants depends strongly on the timing of snowmelt. Moderate genetic differentiation was detected among local populations in every species $\left(F_{\mathrm{ST}}=0.03-0.07\right)$. There was a significant correlation between the geographic distance and genetic distance in the $P$. multivittatum populations, but not in the
\end{abstract}

V. stelleri and G. nipponica populations. On the other hand, a significant correlation between the phenological distance caused by snowmelt timing and genetic distance was detected in the $V$. stelleri and $G$. nipponica populations, but not in the $P$. multivittatum populations. The snowmelt gradient or geographic separation influenced hierarchical genetic structure of these species moderately $\left(F_{\mathrm{RT}}<0.04\right)$. Restriction of gene flow due to phenological separation and possible differential selection along the snowmelt gradient may produce genetic clines at microgeographic scale in these species.

Heredity (2004) 93, 290-298. doi:10.1038/sj.hdy.6800503

Published online 30 June 2004

Keywords: alpine plants; flowering phenology; F-statistics; gene flow; isolation by distance; landscape genetics

\section{Introduction}

Spatial and temporal patterns of gene flow with respect to landscape features have crucial effects on the spatial patterns of genetic variation within a region (Sork et al, 1999; Kudoh, 2001). Landscape influences gene flow not only through spatial location but also because of variation in other traits that limit gene flow, such as flowering phenology in plants. A more precise integration of the landscape context can provide insights into the dynamics of interpopulation gene exchange. Landscape genetics is a new approach to the relationship between landscape features and spatial pattern of genetic variation, which has a potential to detect microevolutionary units in the field (Manel et al, 2003).

Theoretical studies predicted that genetic differentiation among populations should increase as a function of distance when gene flow declines with distance, that is, there is isolation-by-distance (Wright, 1943; Slatkin and Maddison, 1990; Slatkin, 1993). On the other hand, genetic differentiation in plant populations has been documented on a small scale, even when substantial gene flow is possible, if strong selective forces exist in a heterogeneous environment (reviewed in Linhart and Grant, 1996).

In alpine environments, with heavy snowfall, the occurrence of plants within snow-patches (snowbed

Correspondence: AS Hirao, Graduate School of Environmental Earth Science, Hokkaido University, Sapporo 060-0810, Japan.

E-mail: hirao@ees.hokudai.ac.jp

Received 8 April 2003; accepted 19 April 2004; published online 30 June 2004 plants) can have a strong impact on gene flow via pollen flow among patches. The flowering schedule of snowbed plants is fundamentally determined by the timing of snowmelt (Holway and Ward, 1965; Kudo, 1991). As the timing of snowmelt varies among snow-patches, scattered populations of single species can have asynchronous flowering phenologies along a snowmelt gradient. In other words, the flowering phenology of each population might differ even among closely neighboring populations, and an effective barrier to gene flow via pollen flow could occur within a local area. In addition, differential selective forces caused by a snowmelt gradient may influence the genetic variation of snowbed plants, because the temperature regime, soil conditions, and length of the growing season for plants will greatly vary depending on the snowmelt conditions (eg Körner, 1999). Thus, alpine snowbeds can be an interesting experimental system for a landscape genetics approach in which spatial pattern of genetic variation can be compared along two orthogonal gradients, geographic, and phenological distance.

Stanton et al (1997) analyzed the genetic variation of a snowbed herb, Ranunculus adoneus, whose flowering season was determined by the timing of snowmelt, and detected some genetic structure within a snow-patch, but the genetic differentiation along the snowmelt gradient was unclear. To clarify the genetic structure of snowbedplant populations, comparisons of several species on a wider scale may be necessary. The scale of genetic structure should depend on the migration ability (Antonovics et al, 2001) and breeding system of individual species (Hamrick and Godt, 1989) as well as the 
extent of environmental gradients. For example, highly self-fertilizing species often have low genetic diversity within a population, but high genetic differentiation among populations in comparison with outcrossing species (reviewed in Hamrick and Godt, 1989). Thus, the pattern of genetic structure may differ among species even within a local ecosystem. This suggests that the effects of landscape features on microevolutionary process are likely to vary among species.

Asynchronous reproductive phenology among snowbed-plant populations, in addition to their spatial distribution, may create genetically independent units within a local region, or a network of directional gene flow across local populations. In this study, we describe an allozyme-based study of genetic structure of three herbaceous species having different breeding systems; andromonoecy (production of male and hermaphroditic flowers), simultaneous hermaphroditism, and dichogamy (protoandrous flowers). To examine the relationship between landscape features and spatial pattern of genetic variation, we ask the following questions: (1) To what extent do genetic differentiation and gene flow exist among local populations of snowbed plants? (2) Do geographic distance and phenological gradient influence the genetic structure among local populations?

\section{Materials and methods}

\section{Study sites}

This study was conducted in the central part of the Taisetsu Mountains in Hokkaido, northern Japan. Due to heavy snowfall and prevailing northwest winds during the winter, deep snowdrifts are established on southeastern-facing slopes that cause clear gradients of snowmelt timing within a local area. The timing of snowmelt ranges from mid-May around ridges to late August in the center of snow patches. Snow comes again in late September and the ground is usually covered with snow by early October.
In 2000, three sites (Hisago $(\mathrm{H})$, Kaundaira $(\mathrm{K})$, and Goshikigahara $(G)$ ) located within $1 \mathrm{~km}$ from each other were selected (Figure 1). At each site, three plots were set up along a snowmelt gradient. At early snowmelt plots (plot-1), snow disappeared during early to mid-June, at middle snowmelt plots (plot-2) during late June to early July, and at late snowmelt plots (plot-3) around late July. Therefore, these plots were arranged as a $3 \times 3$ matrix of snowmelt conditions and locations (Figure 2a). Geographic locations of individual plots were determined by a hand-held GPS (eTrex, Garmin, USA), then Euclidean distances for pairs of plots were calculated.

\section{Plant species}

Three perennial herb species having wide distribution ranges along snowmelt gradients were selected as target species in this study. Peucedanum multivittatum Maxim. (Umbelliferae) is an andromonoecious herb, in which a terminal umbel has both male and hermaphroditic flowers, and lateral umbels usually have only male flowers. Hermaphroditic flowers of this species show a dichogamous flowering pattern from the male to female phase (protandry). Plant height is $10-30 \mathrm{~cm}$ and clonal growth is rare. Major pollinators are syrphids and other flies, and sometimes rove beetles and bumblebees. Veronica stelleri Pall. ex Link var. longistyla Kitagawa (Scrophuoariaceae) is a hermaphroditic herb, which frequently forms a clonal clamp (mostly $<30 \mathrm{~cm}$ in length). Plant height is $10-20 \mathrm{~cm}$. Each raceme has two to 20 perfect flowers, and flowering occurs gradually from bottom to top with overlapping of two to four flowers. Major pollinators are syrphids and other flies, and sometimes bumblebees. Gentiana nipponica Maxim. (Gentianacea) is small stoloniferous herb forming a small clonal clamp as long as its height $(<15 \mathrm{~cm})$. An inflorescence usually produces one to three dichogamous flowers, which are protandrous. Major pollinators are bumblebees, but syrphids and other flies also visit this species. Seeds of these species do not have any specific

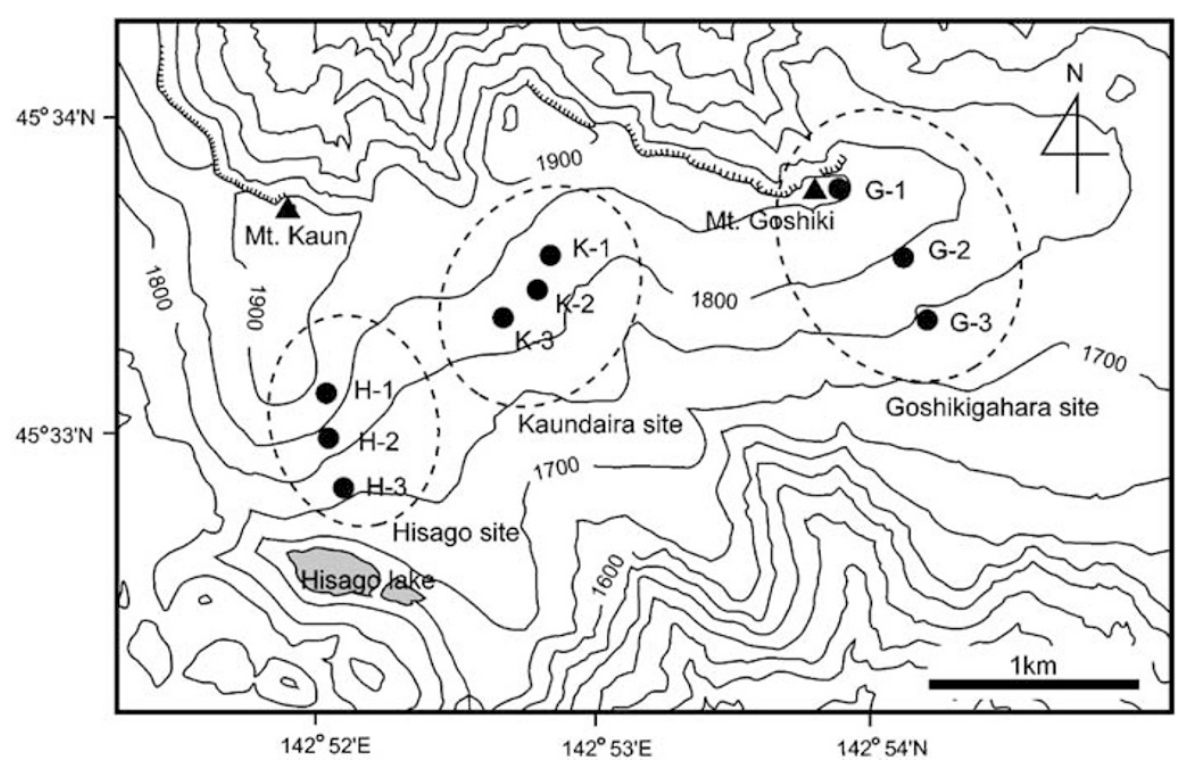

Figure 1 Location of the three study sites: Hisago $(\mathrm{H})$, Kaundaira $(\mathrm{K})$, and Goshikigahara $(\mathrm{G})$. Each site has three plots arranged along the snowmelt gradient: early (1), middle (2), and late snowmelt (3) plots. Plot size is about $20 \times 20 \mathrm{~m}^{2}$. 
292

a
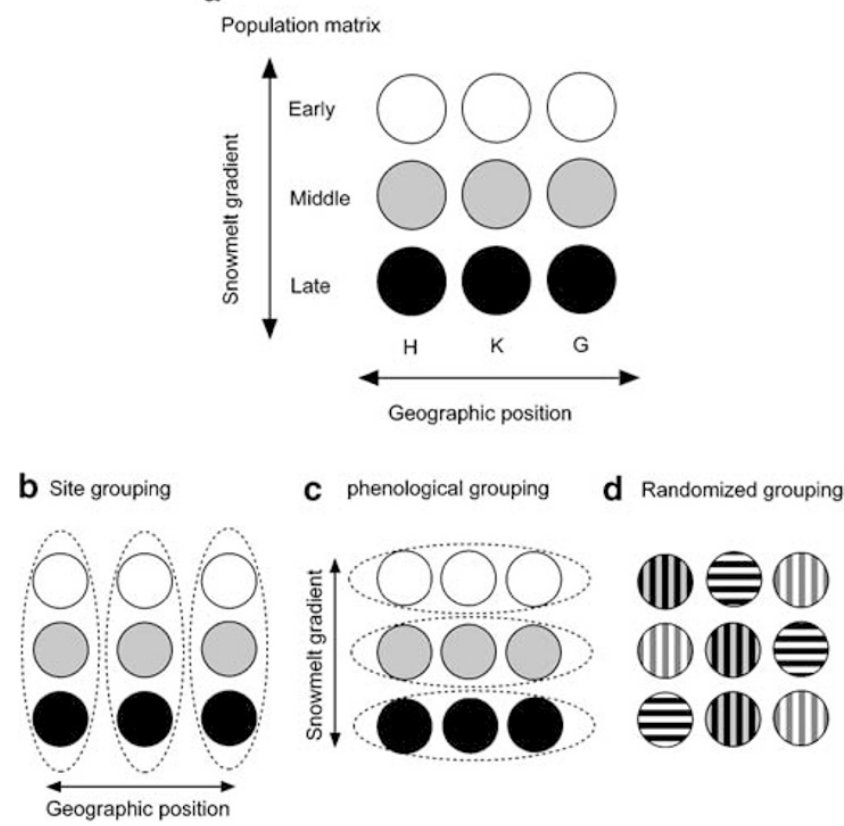

Figure 2 Illustration of the experimental design. (a) Nine plots were arranged as a matrix of three geographic locations ( $\mathrm{H}, \mathrm{K}$, and $\mathrm{G})$ and three snowmelt conditions (early, middle, and late). (b) Site grouping was marked out by three geographic positions. (c) Phenological grouping was marked out by three snowmelt gradients. Populations of the same group had similar flowering phenology across sites. (d) Randomized grouping containing three local populations that did not depend on geographic position or snowmelt gradient.

organ for long-distance dispersal, and seeds are dispersed around the parental plants by gravity.

\section{Phenology}

A local population (single patch) of individual species was identified by phenological and spatial isolation from other patches. The snowmelt day at each plot was determined from the ground temperature measured using automatic loggers (StowAway Tidbit, Onset Co, USA) set at the center of each plot. In all, 40 plants of each species were randomly marked at each plot and the number of opening flowers was counted every 3 to 10 days from June to September in 2000-2002. For individual populations, the day of flowering onset was represented by the median date between the first recognition of flowering and the latest inspection among plants selected in each species. The mean values of flowering onset data over 3 years were used for the analyses.

\section{Electrophoresis}

Leaf material from about 40 individuals was sampled at each plot in 2000 during the anthesis of each species. The interval of sampling was about $1 \mathrm{~m}$ to avoid duplicating same genets. The collected leaves were taken back in a cooler box and stored at $-28^{\circ} \mathrm{C}$ in the laboratory prior to the electrophoresis experiment. Approximately $100 \mathrm{mg}$ of leaf tissue was homogenized in $2.0 \mathrm{ml}$ of extract buffer $(0.1 \mathrm{M}$ Tris- $\mathrm{HCl}(\mathrm{pH} 7.5), 20 \%$ (v/v) glycerol, $0.75 \%$ Tween $80,10 \mathrm{mM}$ dithiothreitol, $0.1 \%$ (v/v) $\beta$-mercaptoethanol, and $75 \mathrm{mg} / \mathrm{ml}$ polyvinylpolyprrolidone). The extracts were loaded on polyacrylamide vertical slab gels after refining by centrifugation at $1500 \mathrm{rpm}$ for $20 \mathrm{~min}$. Electrophoresis was conducted at $4{ }^{\circ} \mathrm{C}, 12 \mathrm{~mA} / \mathrm{cm}^{2}$ for $150 \mathrm{~min}$. The gels were stained for the following enzyme systems, that is, aspartate aminotransferase (AAT; 2.6.1.1), esterase (EST; 3.1.1), glutamic acid dehydrogenase (GDH; 1.4.1.2), glucose-6-phosphate dehydrogenase (G6PD; 1.1.1.49), isocitric acid (IDH; 1.1.1.42), malic acid dehydrogenase (MDH; 1.1.1.37), 6-phosphogluconate dehydrogenase (6PGD; 1.1.1.44), phosphoglucose isomerase (PGI; 5.3.1.9), phosphoglucomutase (PGM; 2.7.5.1), shikimic acid dehydrogenase (SKD; 1.1.1.25), and tetrazolium oxidase (TZO; 1.15.1.1), following the protocol by Tsumura (2001). Loci were numbered starting with the most anodal. In the same way, alleles were identified by letters alphabetically.

\section{Statistical analysis of genetic measurements}

Standard measures of genetic variation, including percent of polymorphic loci $(P)$, mean number of alleles per locus $(A)$, and expected heterozygosity, or gene diversity (He) were calculated using the POPGENE ver.1. 32 program (by Yeh et al, http:/ / www.ualberta.ca/ fyeh/ index.html) for all screened loci. A locus was considered polymorphic if the most common allele had a frequency less than 0.99 . To test whether the allele frequencies depend on phenological gradient, Spearman's rank correlations between allele frequencies for polymorphic loci and the day of flowering onset were calculated in nine populations using the $\mathrm{R}$ package (version 1.62). As the presence of one allele excludes another, only the $n-1$ independent alleles ( $n=$ number of alleles) were analyzed (the most frequent).

We used Weir and Cokerham (1984) estimators of Wright's F-statistics to estimate the genetic structure within and among populations. Using FSTAT (ver.2.9) (http://www.unil.ch.izea/softwares/fstat.html; see Goudet, 1995). The significance was tested using a randomization procedure with 5000 replicates.

Genetic distance between populations was calculated as pairwise $F_{\mathrm{ST}}$ (Reynolds et al, 1983). Phenological distances were determined as the differences in flowering onset (day) between populations. Genetic distance, geographic distance, and phenological distance were expressed as similarity matrixes. The relationships of these measures to each other were assessed using partial Mantel tests (Smouse et al, 1986) to tease apart their effects. Each test was performed for 5000 randomizations with the FSTAT program.

The index of differentiation among groups of populations was computed as $F_{\mathrm{RT}}$ (Hartl and Clark, 1997). The groups of populations were classified by geographic site or phenology (Figure $2 b$ and $c$ ). Coefficients of differentiation among the geographic (= site) groups, $F_{\mathrm{RT}(\mathrm{geo}) \text {, }}$ or the phenological groups, $F_{\mathrm{RT}(\mathrm{phe}) \text {, were computed }}$ from the variance components at different levels of hierarchical subdivision, following Weir and Cokerham (1984). The proportion of genetic variation at each hierarchical level was also calculated from the variance components (Excoffier et al, 1992). To test the extent of hierarchical structure, we randomized the groups according to the scheme illustrated in Figure $2 \mathrm{~d}$ for all 280 combinations and coefficients of differentiation among randomized groups as $F_{\mathrm{RT}(\text { rand) }}$ were computed. 


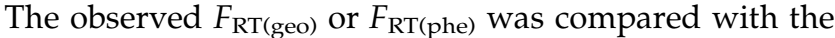
null distribution to assess the significance of the observed value.

\section{Results}

\section{Flowering phenology}

The patterns of snowmelt timing at each plot and flowering phenology of target species were almost constant during 2000 to 2002. As a representative of 3 years, the phenological pattern in 2001 is shown in Figure 3. Although flowering of most individuals in every species lasted shorter than 2 weeks, flowering season varied from mid-June to late of September over the plots and species. The same snowmelt groups (ie early, middle, or late) had similar snowmelt timing, and the flowering season of the same species was overlapped substantially within the same snowmelt groups across the sites. However, isolation of flowering phenology was usually incomplete among different snowmelt categories within each site. Owing to early snowfall in 2001

\section{a Peucedanum multivittatum}
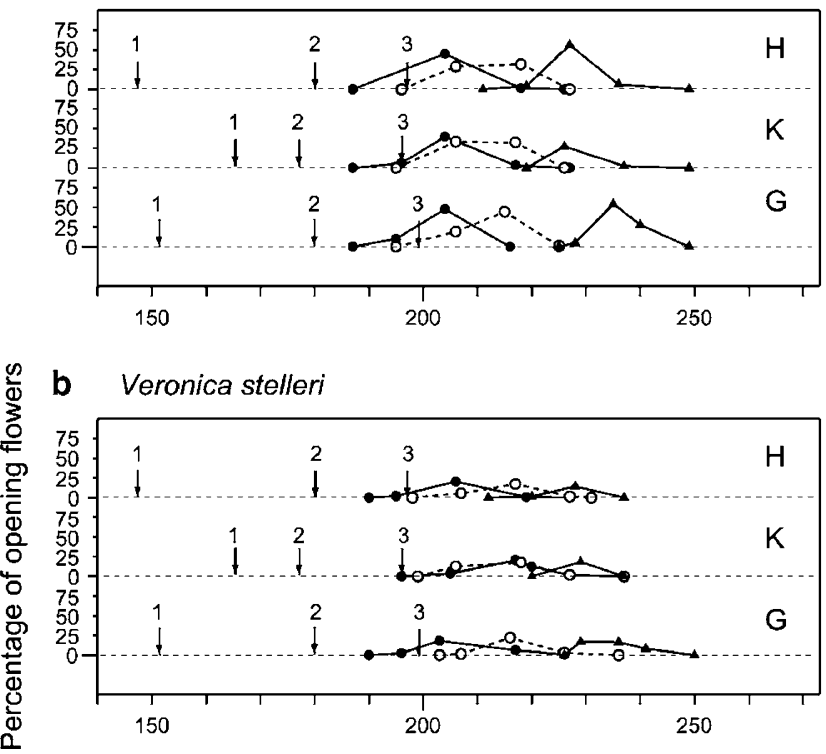

C Gentiana nipponica

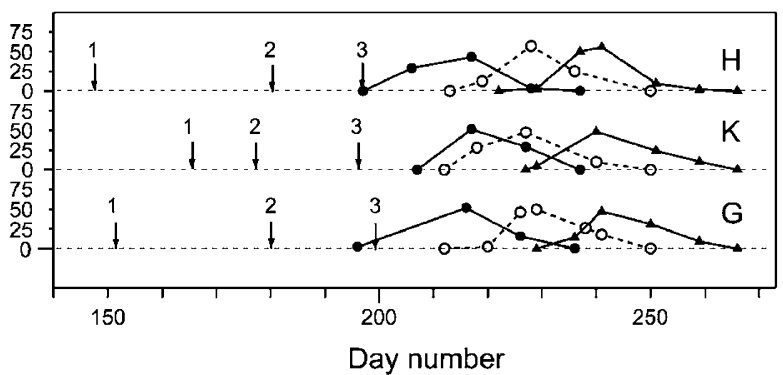

Figure 3 Snowmelt schedule and flowering phenology of three snowbed-herb species at each local population along snowmelt gradients (early: 1 , middle: 2 , and late: 3 ) within each site $(\mathrm{H}, \mathrm{K}$, and $\mathrm{G})$ in 2001. Downward arrow indicates the day of snow disappearance. Curves are the percentage of total flowers counted in anthesis at intervals during the blooming period. Closed circles: early plots; open circles: middle plots; triangles: late plots.
(September 24), G. nipponica was covered with snow before the end of flowering at late snowmelt plots.

\section{Genetic variation}

Seven polymorphic loci of nine loci from seven enzymes resolved in $P$. multivittatum, five polymorphic loci of the 10 loci from seven enzymes resolved in $V$. stelleri, and seven polymorphic loci of 11 loci from six enzymes resolved in G. nipponica were scored (see Appendix A).

The proportion of polymorphic loci $(P)$ varied among populations of $P$. multivittatum and $G$. nipponica but not in $V$. stelleri (Table 1). The average number of alleles per locus $(A)$ was less than two in most populations (Table 1). Gene diversity or expected heterozygosity (He) within populations ranged from 0.065 to 0.154 in P. multivittatum, from 0.044 to 0.138 in V. stelleri, and from 0.065 to 0.178 in G. nipponica (Table 1 ).

Comparisons of allele frequencies among populations revealed that Est-4a and Pgi-2c of $V$. stelleri alleles and Aat-1b, Est-2b, and Pgm-1b of G. nipponica alleles were significantly correlated with phenology as the day of flowering onset $(r=-0.79, P<0.05 ; r=0.86, P<0.01$; $r=-0.87, P<0.01 ; r=-0.85, P<0.01 ; r=-0.70, P<0.05$, respectively). However, none of the alleles were significantly correlated with the day of flowering onset in P. multivittatum $(P>0.05)$.

The mean $F_{\text {IS }}$ over all loci for $P$. multivittatum $(-0.028)$ was not significantly different from zero, indicating complete outcrossing in the adult stage. While the $F_{\text {IS }}$ values of $V$. stelleri and G. nipponica (0.234 and 0.076, respectively) were significantly positive $(P<0.001)$.

\section{Genetic structure}

An index of genetic differentiation among populations, $F_{\mathrm{ST}}$, was not large $(<0.1)$ but significantly greater than zero in every species $(P<0.001)$, indicating the existence of some genetic structure (Table 2). To evaluate the effects of geographic distance and phenological distance on genetic structure, we performed partial Mantel tests (Table 3). The partial correlation between genetic distance and geographic distance was significantly positive in $P$. multivittatum but not in $V$. stelleri or G. nipponica (Figure 4, Table 3). In contrast, positive relationships were detected between genetic distance and phenological distance in $V$. stelleri and G. nipponica but not in P. multivittatum (Figure 4, Table 3). Geographic distance and phenological distance were not correlated in every species (Table 3 ).

Hierarchical analysis of genetic variation showed that the proportion of the 'among-groups' variance component was low $(<4 \%)$, relative to the 'within-populations' component $(>90 \%)$ in every species (Table 2$)$. To test of the significance for hierarchical genetic structure, the observed coefficient of genetic differentiation among groups, $F_{\mathrm{RT} \text { (geo) }}$ (geographic groups) and $F_{\mathrm{RT}(\text { phe) }}$ (phenological groups) were compared with the frequency distribution of the coefficient obtained in randomized groups $F_{\mathrm{RT} \text { (rand) }}$ (Figure 5). Although the variance component among groups was small, significant genetic differentiation was detected among some phonological groups. In $V$. stelleri and $G$. nipponica, $F_{\mathrm{RT}(\mathrm{phe})}$ were significant $(P<0.05)$, while $F_{\mathrm{RT} \text { (geo) }}$ was not. In $P$. multivittatum neither value was significant, although $F_{\mathrm{RT} \text { (geo) }}$ was marginal $(P=0.079)$. These results indicate that 
Table 1 Genetic variation of three snowbed-herb species at each local population

\begin{tabular}{|c|c|c|c|c|c|c|c|c|c|}
\hline \multirow[t]{2}{*}{ Population } & \multicolumn{3}{|c|}{ Peucedanum multivittatum } & \multicolumn{3}{|c|}{ Veronica stelleri } & \multicolumn{3}{|c|}{ Gentiana nipponica } \\
\hline & $\mathrm{P}$ & A & $\mathrm{He}$ & $\mathrm{P}$ & A & $\mathrm{He}$ & $\mathrm{P}$ & A & $\mathrm{He}$ \\
\hline H-1 & 0.67 & 1.71 & 0.131 & 0.50 & 1.50 & 0.044 & 0.55 & 1.55 & 0.065 \\
\hline $\mathrm{H}-2$ & 0.67 & 1.71 & 0.102 & 0.50 & 1.90 & 0.171 & 0.64 & 1.64 & 0.114 \\
\hline H-3 & 0.67 & 1.43 & 0.065 & 0.50 & 1.70 & 0.152 & 0.73 & 2.00 & 0.178 \\
\hline $\mathrm{K}-1$ & 0.67 & 1.57 & 0.121 & 0.50 & 1.70 & 0.096 & 0.64 & 1.82 & 0.159 \\
\hline $\mathrm{K}-2$ & 0.78 & 1.57 & 0.112 & 0.50 & 1.70 & 0.131 & 0.55 & 1.73 & 0.099 \\
\hline $\mathrm{K}-3$ & 0.78 & 1.71 & 0.119 & 0.50 & 1.60 & 0.138 & 0.64 & 1.72 & 0.150 \\
\hline G-1 & 0.67 & 1.86 & 0.121 & 0.50 & 1.60 & 0.120 & 0.55 & 1.64 & 0.124 \\
\hline G-2 & 0.67 & 1.43 & 0.114 & 0.50 & 1.50 & 0.130 & 0.64 & 1.82 & 0.127 \\
\hline G-3 & 0.78 & 2.14 & 0.154 & 0.50 & 1.50 & 0.106 & 0.64 & 1.91 & 0.125 \\
\hline Average & $0.71(0.02)$ & $1.68(0.08)$ & $0.115(0.008)$ & $0.50(0.00)$ & $1.63(0.05)$ & $0.121(0.013)$ & $0.62(0.02)$ & $1.76(0.05)$ & $0.127(0.011)$ \\
\hline Overall & 0.78 & 2.43 & 0.119 & 0.50 & 2.00 & 0.129 & 0.73 & 2.00 & 0.129 \\
\hline
\end{tabular}

$P$ is proportion of polymorphic loci with the 0.99 criteria, $A$ is the mean number of alleles per locus, He is the expected heterozygosity or gene diversity. Standard errors among populations are within parenthesis.

Table 2 Hierarchical analysis of variance of gene frequencies on three target species

\begin{tabular}{|c|c|c|c|}
\hline \multirow[t]{2}{*}{ Variance component } & \multicolumn{2}{|c|}{ Observed partition } & \multirow[t]{2}{*}{ F-statistics } \\
\hline & Variance & $\%$ total & \\
\hline \multicolumn{4}{|l|}{ (a) P. multivittatum } \\
\hline Within populations & 0.403 & 97.46 & $F_{\mathrm{ST}}=0.025^{* * *}$ \\
\hline Among populations/geographical groups & 0.005 & 1.29 & $F_{\mathrm{SR}(\mathrm{geo})}=0.013$ \\
\hline Among geographical groups & 0.005 & 1.25 & $F_{\mathrm{RT}(\text { geo })}=0.012^{*}$ \\
\hline Among populations/phenological groups & 0.009 & 2.50 & $F_{\mathrm{SR}(\mathrm{phe})}=0.020$ \\
\hline Among phenological groups & 0.001 & 0.04 & $F_{\mathrm{RT}(\text { phe })}=0.005$ \\
\hline \multicolumn{4}{|l|}{ (b) V. stelleri } \\
\hline Within populations & 0.602 & 93.4 & $F_{\mathrm{ST}}=0.071^{* * *}$ \\
\hline Among populations/geographical groups & 0.055 & 6.6 & $F_{\mathrm{SR}(\mathrm{geo})}=0.066^{* *}$ \\
\hline Among geographical groups & 0.001 & 0.0 & $F_{\mathrm{RT}(\text { geo })}=0.000$ \\
\hline Among populations/phenological groups & 0.028 & 3.7 & $F_{\mathrm{SR}(\mathrm{phe})}=0.036$ \\
\hline Among phenological groups & 0.027 & 3.6 & $F_{\mathrm{RT}(\text { phe })}=0.036^{* *}$ \\
\hline \multicolumn{4}{|l|}{ (c) G. nipponica } \\
\hline Within populations & 0.673 & 95.9 & $F_{\mathrm{ST}}=0.041^{* * *}$ \\
\hline Among populations/geographical groups & 0.027 & 3.3 & $F_{\mathrm{SR}(\mathrm{geo})}=0.033$ \\
\hline Among geographical groups & 0.001 & 0.8 & $F_{\mathrm{RT}(\mathrm{geo})}=0.008$ \\
\hline Among populations/phenological groups & 0.021 & 2.4 & $F_{\mathrm{SR}(\mathrm{phe})}=0.024$ \\
\hline Among phenological groups & 0.008 & 1.7 & $F_{\mathrm{RT}(\text { phe })}=0.017^{* *}$ \\
\hline
\end{tabular}

${ }^{*} P<0.1 ;{ }^{* * P}<0.5 ;{ }^{* *} P<0.001$, by randomization test.

Table 3 Results of partial Mantel test investigating the relationships between genetic distance and geographic distance or phenological distance on three target species

\begin{tabular}{|c|c|c|c|c|}
\hline Species & Mantel test & $\mathrm{r}$ & $\beta$ & P-value \\
\hline \multirow[t]{3}{*}{ P. multivittatum } & $(\mathrm{GEN} \times \mathrm{GEO}) . \mathrm{PHE}$ & 0.429 & 0.013 & 0.0095 \\
\hline & $(\mathrm{GEN} \times \mathrm{PHE}) \cdot \mathrm{GEO}$ & -0.061 & 0.000 & 0.7370 \\
\hline & $\mathrm{GEO} \times \mathrm{PHE}$ & -0.079 & -0.749 & 0.6530 \\
\hline \multirow[t]{3}{*}{ V. stelleri } & $(\mathrm{GEN} \times \mathrm{GEO}) . \mathrm{PHE}$ & -0.155 & -0.006 & 0.3825 \\
\hline & $(\mathrm{GEN} \times \mathrm{PHE}) . \mathrm{GEO}$ & 0.411 & -0.002 & 0.0130 \\
\hline & $\mathrm{GEO} \times \mathrm{PHE}$ & -0.091 & -0.904 & 0.6000 \\
\hline \multirow[t]{3}{*}{ G. nipponica } & $(\mathrm{GEN} \times \mathrm{GEO}) . \mathrm{PHE}$ & -0.098 & -0.001 & 0.5725 \\
\hline & (GEN $\times$ PHE).GEO & -0.558 & -0.002 & 0.0005 \\
\hline & $\mathrm{GEO} \times \mathrm{PHE}$ & -0.088 & -0.799 & 0.6230 \\
\hline
\end{tabular}

'(GEN $\times$ GEO).PHE' tests the partial correlation between genetic distance and geographical distance in which the effect of phonological distance was controlled, '(GEN $\times$ PHE).GEO' tests the partial correlation between genetic distance and phonological distance in which the effect of geographic distance was controlled, and 'GEO $\times \mathrm{PHE}^{\prime}$ is a simple Mantel test between the explaining variables. $r$ is correleation coefficient and $\beta$ is regression coefficient. 
a Peucedanum multivittatum
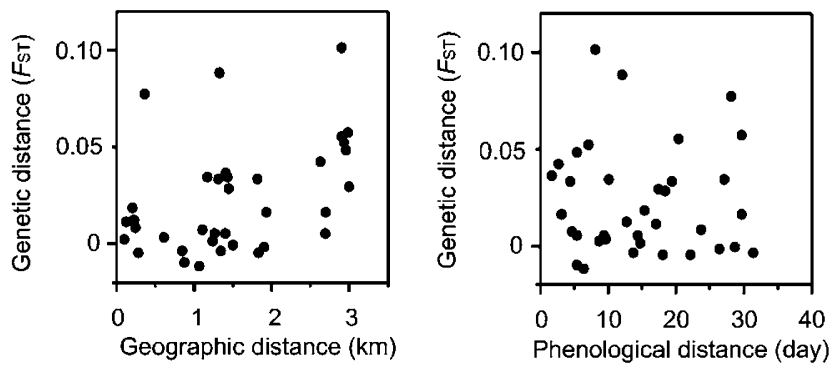

b Veronica stelleri
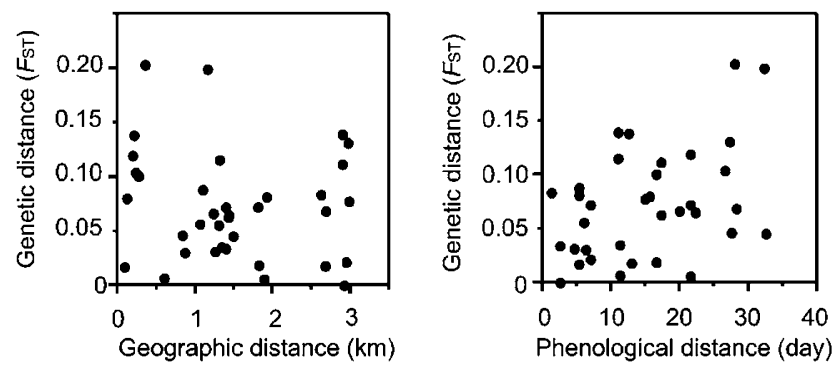

C Gentiana nipponica
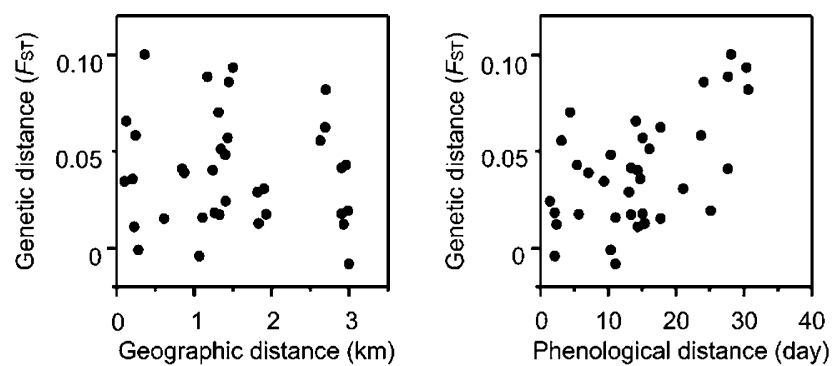

Figure 4 Relationships between genetic distance (pairwise $F_{\mathrm{ST}}$ ) and geographic or phenological distance, for all pairs of nine populations of three snowbed-herb species. For statistical results by partial Mantel test, see Table 3.

hierarchical genetic structures of target species depend on either geographic or phenological factor.

\section{Discussion}

Significant genetic differentiation was observed for all the three species among populations within a restricted area. When effective gene flow is restricted due to regional-scale isolation, the degree of genetic differentiation among populations is generally high, and $F_{\mathrm{ST}}$ or $G_{S T}$ values are often greater than 0.1 (eg Murawski and Hamrick, 1990; Godt and Hamrick, 1993; Tani et al, 1996). In this study, however, the level of genetic differentiation $\left(F_{\mathrm{ST}}\right)$ was less than 0.1 (Table 2), suggesting effective gene flow among local populations. The level of genetic differentiation $\left(F_{\mathrm{ST}}=0.03-0.07\right)$ corresponded with values found in comparable studies. For example, in the alpine herb Primula caneifolia var. hakusanensis, genetic diversity showed that $4 \%$ of genetic variation existed within mountain regions among populations and 54\% among mountain region, $42 \%$ within population (Shindo et al, 1995). a Peucedanum multivittatum

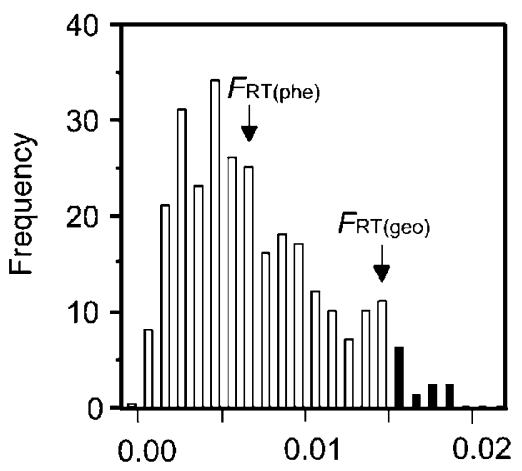

b Veronica stelleri

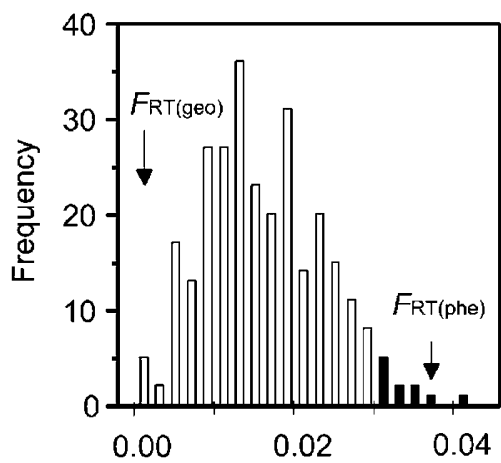

c Gentiana nipponica

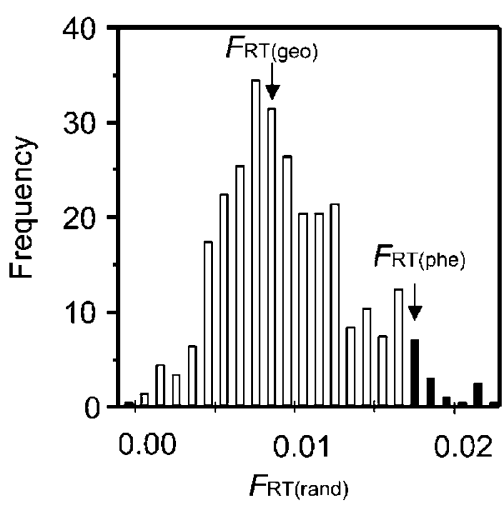

Figure 5 Distribution of coefficient of differentiation among

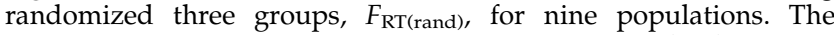
observed values of coefficient among geographic (site) groups,

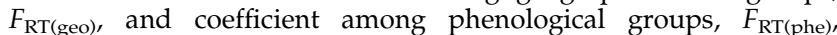
were shown. Closed bars indicate a significant level $(<5 \%)$. For F-statistics, see Table 2.

Only a few reports have detected isolation-by-distance at a low $F_{\mathrm{ST}}$ level $(<0.1$; Hall et al, 1994; Giles and Goudet, 1997; Alexandersson and Ågren, 2000). Among the three target species studied here, geographic isolation-by-distance was detected only in P. multivittatum (Figure 4, Table 3). On the other hand, an effect of phenological distance on genetic variation was detected in $V$. stelleri and G. nipponica (Figure 4, Table 3), suggesting the importance of pollen flow on the formation of genetic structures.

Pollen dispersal is a primary mechanism of gene flow over long distances in most entomophilous plants 
(Levin, 1987). Owing to the fact that the foraging flights by bumblebees are often more than $5 \mathrm{~km}$ (Heinrich, 1979), lack of geographic differentiation and strong phenological effects on genetic distance observed in bumblebee-pollinated G. nipponica may be caused by frequent long-distance pollen flow. In contrast, significant geographic effect in $P$. multivittatum may reflect local pollen flow by dipteran insects. As seeds are large $(7-8 \mathrm{~mm})$ and likely to be dispersed by gravity in this species, frequent gene flow via seed dispersal is considered unlikely.

Clinal changes in allele frequency may occur due to unidirectional gene flow from early to late flowering populations (or reverse) if a partial overlap of flowering occurs, as predicted by the stepping-stone model (Kimura and Weiss, 1964). In addition to phenological segregation, differential natural selection along a snowmelt gradient might be important for the development of spatial patterns of genetic variation. Some allozyme studies at microgeographic scales suggest that changes in gene frequencies reflecting environmental gradients are indeed caused by natural selection (eg Allard et al, 1993; Linhart and Grant, 1996; Prentice et al, 2000). In our study, only species having excess homozygotes within populations showed a significant genetic structure along the phenological gradient. These species, that is, V. stelleri and $G$. nipponica, have clonal growth by stolons, so the selection might be on linked loci, rather than the allozymes themselves (eg Hedrick, 1986). In conclusion, assemblage of local populations of snowbed plants forms a hierarchical genetic structure depending on the geographic location and/or the snowmelt gradient as landscape features. The snowmelt gradient creates local pattern of gene flow due to phenological separation and possibly selection. In addition, breeding system of individual species may be important to understand the relationship between landscape features and spatial pattern of genetic variation, although further studies are needed (see Ingvarsson and Giles, 1999). Recently, the effects of global climate change on alpine ecosystems have raised concerns not only from the viewpoint of vegetational change over the geographic range (eg Grabherr et al, 1994) but also the reproductive characteristics of individual species (Inouye and McGuire, 1991; Inouye et al, 2002). If global temperature changes alter snowmelt patterns in alpine regions, the flowering phenology of alpine plants will be highly influenced, resulting in changes in patterns of gene flow and/or the intensity of selective forces and thus the spatial pattern of genetic variation.

\section{Acknowledgements}

We thank T Kasagi, Y Shimono, M Kimura, Y Taguchi, and S Hatano for their help with the fieldwork; M Ohara for his advice on the allozyme experiment; $\mathrm{T}$ Nagamitsu and $\mathrm{H}$ Tomimatsu for their suggestions with regard to the genetic analysis; $\mathrm{T}$ Kubo for performing the permutation tests; and I Hanski for his valuable suggestions on this study. This study was supported by a grant-in aid (\#31440226) from the Japanese Ministry of Education, Culture, Sports, Science, and Technology.

\section{References}

Alexandersson R, Ågren J (2000). Genetic structure in the nonrewarding, bumblebee-pollinated orchid Calypso bulbosa. Heredity 85: 401-409.

Allard RW, García P, Sáenz-de-Miera LE, Pérez de la Vega M (1993). Evolution of multilocus genetic structure in Avena hirtula and Avena barbata. Genetics 135: 1125-1139.

Antonovics J, Newman TJ, Best J (2001). Spatially explicit studies on the ecology and genetics of population margins. In: Silvertown J, Antonovics J (eds) Integrating Ecology and Evolution in a Spatial Context. Blackwell Scientific: London, pp 97-116.

Excoffier L, Smouse PE, Quattro JM (1992). Analysis of molecular variance inferred from metric distances among DNA haplotypes: application to human mitochondrial DNA restriction data. Genetics 131: 479-491.

Giles BE, Goudet J (1997). Genetic differentiation in Silene dioica metapopulations: estimation of spatio-temporal effects in a successional plant species. Am Nat 149: 507-526.

Godt MJ, Hamrick JL (1993). Genetic diversity and population structure in Tradescantia hirsuticaulis (Commelinaceae). Am J Bot 80: 959-966.

Goudet J (1995). FSTAT V1.2: a computer program to calculate F-statistics. J Heredity 86: 485-486.

Grabherr G, Gottfried M, Pauli H (1994). Climate effects on mountain plants. Nature 369: 448.

Hall P, Orrell LC, Bawa KS (1994). Genetic diversity and mating system in a tropical tree, Carapa guianensis (Meliaceae). Am J Bot 81: 1104-1111.

Hamrick JL, Godt MJ (1989). Allozyme diversity in plant species. In: Brown AHD, Clegg MT, Kanler AL, Weir BS (eds) Plant Population Genetics Breeding and Genetic Resources. Sinauer Associates: Sunderland, USA, pp 43-63.

Hartl DL, Clark AG (1997). Principles of Population Genetics 3rd edn. Sinauer Associates, Inc. Sunderland, MA

Hedrick PW (1986). Genetic polymorphism in heterogeneous environments: a decade later. Annu Rev Ecol Syst 17: 535-566.

Heinrich B (1979). Bumblebee Economics. Harvard University Press: Cambridge, MA.

Holway JG, WARD RT (1965). Phenology of alpine plants in northern Colorado. Ecology 46: 73-83.

Ingvarsson PK, Giles BE (1999). Kin-structured colonization and small-scale genetic differentiation in Silene dioica. Evolution 53: 605-611.

Inouye DW, Mcguire AD (1991). Effects of snowpack on timing and abundance of flowering in Delphinium nelsonii (Ranunculaceae): implications for climate change. Am J Bot 78: 997-1001.

Inouye DW, Morales MA, Dodge GJ (2002). Variation in timing and abundance of flowering by Delphinium barbeyi (Ranunculaceae): the roles of snowpack, frost, and La Niña, in the context of climate change. Oecologia 130: 543-550.

Kimura M, Weiss GH (1964). The stepping stone model of population structure and the decrease of genetic correlation with distance. Genetics 49: 561-576.

Körner C (1999). Alpine Plant Life: Functional Plant Ecology of High Mountain Ecosystems. Springer-Verlag: Berlin, Heidelberg.

Kudo G (1991). Effects of snow-free period on the phenology of alpine plants inhabiting snow patches. Arct Alp Res 23: 436-443.

Kudoh H (2001). Gene flow among plant populations in ecological landscape (in Japanese). Jpn J Ecol 84: 1285-1293.

Levin DA (1987). Local differentiation and the breeding structure of plant populations. In: Gottlieb LD, Jain SK (eds) Plant Evolutionary Biology. Chapman \& Hall: London, pp 305-329.

Linhart YB, Grant MC (1996). Evolutionary significance of local genetic differentiation in plants. Annu Rev Ecol Syst 27: 237-277. 
Manel S, Schwartz MK, Luikart G, Taberlet P (2003). Landscape genetics: combining landscape ecology and population genetics. Trends Ecol Evol 18: 189-197.

Murawski DA, Hamrick JL (1990). Local genetic and clonal structure in the tropical terrestrial bromeliad, Aechmea magdalenae. Am J Bot 77: 1201-1208.

Prentice HC, Lönn M, Lager H, Rosén E, Van Der Maarel E (2000). Changes in allozyme frequencies in Festuca ovina populations after a 9-year nutrient/water experiment. J Ecol 88: 331-347.

Reynolds J, Weir BS, Cockerham CC (1983). Estimation of the coancestry coefficient: basis for a short-tern genetic distance. Genetics 105: 767-779.

Shindo S, Zento H, Watano Y, Kinoshita E, Ueda K, Yonezawa K et al (1995). Conservation biology of Primula cuneifolia var. hakusanensis: genetic variation and differentiation of populations (in Japanese). J Phytogeogr Taxon 43: 103-109.

Slatkin M (1993). Isolation by distance in equilibrium and nonequilibrium populations. Evolution 47: 264-279.

Slatkin M, Maddison W (1990). Detecting isolation by distance using phylogenies of genes. Genetics 126: 249-260.

Smouse PE, Long JC, Sokal RR (1986). Multiple regression and correlation extensions of the Mantel test of matrix correspondence. Syst Zool 35: 627-632.
Sork VL, Nason J, Campbell DR, Fernendez JF (1999). Landscape approaches to historical and contemporary gene flow in plants. Trends Ecol Evol 14: 219-224.

Stanton ML, Galen ML, Shore J (1997). Population structure along a steep environmental gradient: consequences of flowering time and habitat variation in the snow buttercup Ranunculus adoneus. Evolution 51: 79-94.

Tani N, Tomaru N, Araki M, Ohba K (1996). Genetic diversity and differentiation in populations of Japanese stone pine (Pinus pumila) in Japan. Can J Forest Res 26 1454-1462.

Tsumura Y (2001). Allozyme experiment method. In: The Society for the Study of Species Biology (eds) Molecular Ecology of Woody Species (in Japanese) Bun-ichi sogo shuppan Co.: Tokyo, pp 183-219.

Weir BS, Cokerham CC (1984). Estimating F-statistics for the analysis of population structure. Evolution 38: 1358-1370.

Wright S (1943). Isolation by distance. Genetics 28: 114-138.

\section{Appendix A}

Allele frequencies of loci are seen in Tables A1-A3.

Table A1 Allele frequencies for nine loci of P. multivittatum

\begin{tabular}{|c|c|c|c|c|c|c|c|c|c|c|c|}
\hline \multirow[t]{2}{*}{ Locus } & \multirow[t]{2}{*}{ Allele } & \multicolumn{10}{|c|}{ Population } \\
\hline & & $H-1(\mathrm{n}=40)$ & $H-2(\mathrm{n}=40)$ & $H-3(\mathrm{n}=40)$ & $K-1(\mathrm{n}=39)$ & $K-2(\mathrm{n}=40)$ & $K-3(\mathrm{n}=40)$ & $G-1(n=40)$ & $G-2(n=40)$ & $G-3(n=40)$ & Overall $(\mathrm{n}=399)$ \\
\hline \multirow[t]{2}{*}{$A A T-1^{*}$} & a & 0.086 & 0.035 & 0.013 & 0.039 & 0.025 & 0.064 & 0.019 & 0.025 & 0.050 & 0.039 \\
\hline & $\mathrm{b}$ & 0.914 & 0.966 & 0.988 & 0.962 & 0.975 & 0.936 & 0.982 & 0.975 & 0.950 & 0.961 \\
\hline \multirow[t]{2}{*}{$A A T-2^{*}$} & a & 0.707 & 0.638 & 0.825 & 0.744 & 0.838 & 0.769 & 0.611 & 0.625 & 0.725 & 0.728 \\
\hline & $\mathrm{b}$ & 0.294 & 0.362 & 0.175 & 0.256 & 0.163 & 0.231 & 0.389 & 0.375 & 0.275 & 0.272 \\
\hline \multirow[t]{2}{*}{ EST-2* } & a & 0.310 & 0.155 & 0.090 & 0.000 & 0.000 & 0.000 & 0.000 & 0.000 & 0.075 & 0.062 \\
\hline & $\mathrm{b}$ & 0.690 & 0.845 & 0.910 & 1.000 & 1.000 & 1.000 & 1.000 & 1.000 & 0.925 & 0.938 \\
\hline$G D H$ & a & 1.000 & 1.000 & 1.000 & 1.000 & 1.000 & 1.000 & 1.000 & 1.000 & 1.000 & 1.000 \\
\hline \multirow[t]{2}{*}{$6 P G D-1^{*}$} & a & 0.362 & 0.259 & 0.269 & 0.288 & 0.275 & 0.474 & 0.278 & 0.475 & 0.213 & 0.324 \\
\hline & $\mathrm{b}$ & 0.638 & 0.741 & 0.731 & 0.713 & 0.725 & 0.526 & 0.722 & 0.525 & 0.788 & 0.677 \\
\hline \multirow[t]{3}{*}{$P G M-1^{*}$} & a & 0.000 & 0.000 & 0.000 & 0.000 & 0.000 & 0.000 & 0.000 & 0.000 & 0.025 & 0.003 \\
\hline & $\mathrm{b}$ & 0.948 & 0.948 & 0.910 & 0.938 & 0.850 & 0.949 & 0.870 & 0.838 & 0.813 & 0.893 \\
\hline & c & 0.052 & 0.052 & 0.090 & 0.063 & 0.150 & 0.051 & 0.130 & 0.163 & 0.163 & 0.104 \\
\hline \multirow[t]{3}{*}{$S K D-1^{*}$} & a & 0.190 & 0.207 & 0.321 & 0.188 & 0.338 & 0.321 & 0.278 & 0.375 & 0.350 & 0.291 \\
\hline & $\mathrm{b}$ & 0.810 & 0.793 & 0.680 & 0.813 & 0.663 & 0.680 & 0.722 & 0.625 & 0.638 & 0.707 \\
\hline & c & 0.000 & 0.000 & 0.000 & 0.000 & 0.000 & 0.000 & 0.000 & 0.000 & 0.013 & 0.002 \\
\hline$S K D-2$ & a & 1.000 & 1.000 & 1.000 & 1.000 & 1.000 & 1.000 & 1.000 & 1.000 & 1.000 & 1.000 \\
\hline \multirow[t]{3}{*}{$\mathrm{TZO}^{*}$} & a & 0.000 & 0.000 & 0.000 & 0.000 & 0.000 & 0.000 & 0.000 & 0.000 & 0.013 & 0.002 \\
\hline & $\mathrm{b}$ & 1.000 & 1.000 & 1.000 & 1.000 & 0.988 & 0.987 & 1.000 & 1.000 & 0.975 & 0.994 \\
\hline & c & 0.000 & 0.000 & 0.000 & 0.000 & 0.013 & 0.013 & 0.000 & 0.000 & 0.013 & 0.005 \\
\hline
\end{tabular}

*Polymorphic loci (<0.99 level). 
Table A2 Allele frequencies for 10 loci of $V$. stelleri

\begin{tabular}{|c|c|c|c|c|c|c|c|c|c|c|c|}
\hline \multirow[t]{2}{*}{ Locus } & \multicolumn{11}{|c|}{ Population } \\
\hline & Allele & $H-1(\mathrm{n}=39)$ & $H-2(\mathrm{n}=40)$ & $H-3(\mathrm{n}=38)$ & $K-1(\mathrm{n}=40)$ & $K-2(\mathrm{n}=38)$ & $K-3(\mathrm{n}=40)$ & $G-1(\mathrm{n}=40)$ & $G-2(\mathrm{n}=40)$ & $G-3(\mathrm{n}=40)$ & Overall $(\mathrm{n}=355)$ \\
\hline \multirow[t]{2}{*}{$A A T-2^{*}$} & a & 0.949 & 0.650 & 0.737 & 0.913 & 0.868 & 0.575 & 0.713 & 0.613 & 0.863 & 0.764 \\
\hline & $\mathrm{b}$ & 0.051 & 0.350 & 0.263 & 0.087 & 0.132 & 0.125 & 0.287 & 0.388 & 0.138 & 0.236 \\
\hline \multirow[t]{6}{*}{ EST-1* } & a & 0.000 & 0.013 & 0.000 & 0.013 & 0.000 & 0.000 & 0.000 & 0.000 & 0.000 & 0.003 \\
\hline & $\mathrm{b}$ & 0.026 & 0.087 & 0.053 & 0.025 & 0.013 & 0.100 & 0.013 & 0.063 & 0.025 & 0.045 \\
\hline & c & 0.000 & 0.038 & 0.026 & 0.038 & 0.079 & 0.013 & 0.100 & 0.063 & 0.000 & 0.039 \\
\hline & d & 0.974 & 0.750 & 0.921 & 0.925 & 0.895 & 0.888 & 0.888 & 0.875 & 0.975 & 0.899 \\
\hline & $\mathrm{e}$ & 0.000 & 0.000 & 0.000 & 0.000 & 0.000 & 0.000 & 0.000 & 0.000 & 0.000 & 0.000 \\
\hline & $\mathrm{f}$ & 0.000 & 0.113 & 0.000 & 0.000 & 0.013 & 0.000 & 0.000 & 0.000 & 0.000 & 0.014 \\
\hline EST-2 & a & 1.000 & 1.000 & 1.000 & 1.000 & 1.000 & 1.000 & 1.000 & 1.000 & 1.000 & 1.000 \\
\hline \multirow[t]{2}{*}{$E S T-4^{*}$} & a & 0.974 & 0.825 & 0.526 & 0.763 & 0.724 & 0.700 & 0.838 & 0.900 & 0.637 & 0.765 \\
\hline & $\mathrm{b}$ & 0.026 & 0.175 & 0.474 & 0.238 & 0.276 & 0.300 & 0.163 & 0.100 & 0.363 & 0.235 \\
\hline$G D H$ & a & 1.000 & 1.000 & 1.000 & 1.000 & 1.000 & 1.000 & 1.000 & 1.000 & 1.000 & 1.000 \\
\hline$M D H-2$ & a & 1.000 & 1.000 & 1.000 & 1.000 & 1.000 & 1.000 & 1.000 & 1.000 & 1.000 & 1.000 \\
\hline $6 P G D$ & a & 1.000 & 1.000 & 1.000 & 1.000 & 1.000 & 1.000 & 1.000 & 1.000 & 1.000 & 1.000 \\
\hline PGI-1 & a & 1.000 & 1.000 & 1.000 & 1.000 & 1.000 & 1.000 & 1.000 & 1.000 & 1.000 & 1.000 \\
\hline \multirow[t]{4}{*}{ PGI-2* } & a & 0.000 & 0.025 & 0.000 & 0.000 & 0.000 & 0.000 & 0.000 & 0.000 & 0.000 & 0.003 \\
\hline & b & 0.974 & 0.950 & 0.855 & 0.988 & 0.987 & 0.875 & 0.988 & 1.000 & 0.988 & 0.956 \\
\hline & c & 0.000 & 0.025 & 0.118 & 0.013 & 0.013 & 0.125 & 0.000 & 0.000 & 0.013 & 0.034 \\
\hline & d & 0.026 & 0.000 & 0.026 & 0.000 & 0.000 & 0.000 & 0.013 & 0.000 & 0.000 & 0.007 \\
\hline \multirow[t]{2}{*}{$\mathrm{TZO}^{*}$} & a & 0.103 & 0.313 & 0.118 & 0.150 & 0.329 & 0.013 & 0.163 & 0.275 & 0.163 & 0.181 \\
\hline & b & 0.897 & 0.688 & 0.882 & 0.850 & 0.671 & 0.988 & 0.838 & 0.725 & 0.838 & 0.819 \\
\hline
\end{tabular}

*Polymorphic loci $(<0.99$ level $)$.

Table A3 Allele frequencies for 11 loci of G. nipponica

\begin{tabular}{|c|c|c|c|c|c|c|c|c|c|c|c|}
\hline \multirow[t]{2}{*}{ Locus } & \multirow[t]{2}{*}{ Allele } & \multicolumn{10}{|c|}{ Population } \\
\hline & & $H-1(\mathrm{n}=39)$ & $H-2(\mathrm{n}=40)$ & $H-3(\mathrm{n}=40)$ & $K-1(\mathrm{n}=40)$ & $K-2(\mathrm{n}=40)$ & $K-3(\mathrm{n}=40)$ & $G-1(\mathrm{n}=28)$ & $G-2(\mathrm{n}=40)$ & $G-3(\mathrm{n}=40)$ & Overall $(\mathrm{n}=347)$ \\
\hline \multirow[t]{2}{*}{$A A T-1^{*}$} & a & 0.000 & 0.050 & 0.138 & 0.038 & 0.000 & 0.087 & 0.018 & 0.038 & 0.075 & 0.049 \\
\hline & $\mathrm{b}$ & 1.000 & 0.950 & 0.863 & 0.963 & 1.000 & 0.913 & 0.982 & 0.963 & 0.925 & 0.951 \\
\hline \multirow{2}{*}{$A A T-3^{*}$} & a & 0.962 & 0.950 & 0.888 & 0.963 & 0.988 & 0.950 & 0.946 & 0.988 & 0.963 & 0.955 \\
\hline & $\mathrm{b}$ & 0.038 & 0.050 & 0.113 & 0.038 & 0.013 & 0.050 & 0.054 & 0.013 & 0.038 & 0.045 \\
\hline \multirow[t]{2}{*}{$E S T-1^{*}$} & a & 0.179 & 0.145 & 0.287 & 0.188 & 0.175 & 0.138 & 0.393 & 0.238 & 0.175 & 0.213 \\
\hline & $\mathrm{b}$ & 0.821 & 0.855 & 0.713 & 0.813 & 0.825 & 0.863 & 0.607 & 0.763 & 0.825 & 0.787 \\
\hline \multirow[t]{2}{*}{$E S T-2^{*}$} & a & 0.013 & 0.079 & 0.313 & 0.087 & 0.150 & 0.300 & 0.000 & 0.125 & 0.113 & 0.131 \\
\hline & $\mathrm{b}$ & 0.987 & 0.921 & 0.688 & 0.913 & 0.850 & 0.700 & 1.000 & 0.875 & 0.888 & 0.869 \\
\hline \multirow[t]{4}{*}{ EST-3* } & a & 0.000 & 0.000 & 0.025 & 0.000 & 0.000 & 0.000 & 0.000 & 0.000 & 0.013 & 0.004 \\
\hline & $\mathrm{b}$ & 0.974 & 0.947 & 0.888 & 0.775 & 0.938 & 0.988 & 0.929 & 0.900 & 0.950 & 0.921 \\
\hline & c & 0.000 & 0.000 & 0.063 & 0.050 & 0.013 & 0.013 & 0.071 & 0.063 & 0.013 & 0.032 \\
\hline & d & 0.026 & 0.053 & 0.025 & 0.175 & 0.050 & 0.000 & 0.000 & 0.038 & 0.025 & 0.043 \\
\hline G6PD-1 & a & 1.000 & 1.000 & 1.000 & 1.000 & 1.000 & 1.000 & 1.000 & 1.000 & 1.000 & 1.000 \\
\hline \multirow[t]{3}{*}{ PGM-1* } & a & 0.090 & 0.217 & 0.025 & 0.175 & 0.044 & 0.138 & 0.125 & 0.113 & 0.188 & 0.124 \\
\hline & $\mathrm{b}$ & 0.910 & 0.783 & 0.763 & 0.800 & 0.926 & 0.713 & 0.839 & 0.850 & 0.763 & 0.816 \\
\hline & c & 0.000 & 0.000 & 0.213 & 0.025 & 0.029 & 0.150 & 0.036 & 0.038 & 0.050 & 0.060 \\
\hline$P G M-2$ & a & 1.000 & 1.000 & 1.000 & 1.000 & 1.000 & 1.000 & 1.000 & 1.000 & 1.000 & 1.000 \\
\hline$M D H-2$ & a & 1.000 & 1.000 & 1.000 & 1.000 & 1.000 & 1.000 & 1.000 & 1.000 & 1.000 & 1.000 \\
\hline \multirow[t]{2}{*}{ TZO-1* } & a & 0.051 & 0.039 & 0.025 & 0.300 & 0.138 & 0.138 & 0.196 & 0.150 & 0.100 & 0.126 \\
\hline & $\mathrm{b}$ & 0.949 & 0.961 & 0.975 & 0.700 & 0.863 & 0.863 & 0.804 & 0.850 & 0.900 & 0.874 \\
\hline \multirow[t]{2}{*}{ TZO-2 } & a & 1.000 & 1.000 & 0.988 & 1.000 & 1.000 & 1.000 & 1.000 & 1.000 & 1.000 & 0.999 \\
\hline & $\mathrm{b}$ & 0.000 & 0.000 & 0.013 & 0.000 & 0.000 & 0.000 & 0.000 & 0.000 & 0.000 & 0.001 \\
\hline
\end{tabular}

*Polymorphic loci $(<0.99$ level $)$. 